\title{
Nitrogênio e densidade de plantio na avaliação econômica e qualidade de frutos de abacaxizeiro ${ }^{1}$
}

\author{
Deivisson Ferreira da Silva², Rodinei Facco Pegoraro ${ }^{2}$, \\ Ananias Costa Medeiros 2 , Paulo Augusto Pereira Lopes ${ }^{2}$, Maurício Mendes Cardoso ${ }^{3}$, Victor Martins Maia ${ }^{2}$
}

\begin{abstract}
Nitrogen and plant density in the economic evaluation and fruit quality of pineapple

The appropriate use of nitrogen fertilization and higher population densities increase the pineapple yield and can improve economic returns. This study aimed to evaluate the economic return and postharvest characteristics of irrigated Vitória pineapple under different nitrogen $(\mathrm{N})$ sources and doses, as well as the increase in population density. A randomized blocks design with three replications was installed in a $2 \times 5 \times 4$ factorial scheme, corresponding to two $\mathrm{N}$ sources (urea and cattle manure), five $\mathrm{N}$ doses $\left(0 \mathrm{~g}_{\text {plant }}{ }^{-1}, 5 \mathrm{~g}_{\text {plant }}{ }^{-1}, 10 \mathrm{~g}_{\text {plant }}{ }^{-1}, 15 \mathrm{~g} \mathrm{plant}^{-1}\right.$ and 20 g plant $\left.^{-1}\right)$ and four densities (51,282 plants ha $^{-1}, 76,923$ plants ha ${ }^{-1}$, 90,909 plants ha ${ }^{-1}$ and 126,984 plants ha $\left.{ }^{-1}\right)$. The $\mathrm{N}$ sources did not affect the $\mathrm{pH}$, total titratable acidity and total soluble solids/total titratable acidity ratio (TSS/TTA). However the TSS content was higher in plants fertilized with cattle manure. The plants density did not affect the quality of postharvest fruit. The increase of $\mathrm{N}$ doses supplied by urea and cattle manure influenced only the total titratable acidity of the fruits. The combination of $20 \mathrm{~g} \mathrm{plant}^{-1}$ of $\mathrm{N}$-manure and a population of 126,984 plants $^{-1} \mathrm{r}^{-1}$ resulted in the maximum partial net income of R $\$ 132,096.48$, however, the dose of 19.75 g plant $^{-1}$ of N-urea, in the population of $119,686.00$ plants ha $^{-1}$, reached a partial net income of $\mathrm{R} \$ 154,997.15$.
\end{abstract}

KEY-WORDS: Ananas comosus var. comosus; total soluble solids; economic return.

\section{INTRODUÇÃO}

O abacaxizeiro é uma das fruteiras tropicais mais cultivadas no mundo. Filipinas, Brasil, Costa Rica, Tailândia e China são os principais produtores mundiais (FAO 2010). A produção brasileira dessa fruta, em 2014, foi de 1,58 bilhões de frutos, em área colhida de 59.981 mil hectares, sendo os principais

\section{RESUMO}

A utilização adequada da adubação nitrogenada e o aumento da densidade populacional incrementam a produtividade do abacaxizeiro e podem aumentar o retorno econômico. Objetivou-se avaliar a rentabilidade econômica e as características de qualidade pós-colheita do abacaxizeiro Vitória irrigado, sob diferentes fontes e doses de nitrogênio (N), bem como o aumento da densidade populacional. Utilizou-se o delineamento em blocos casualizados, com três repetições, em esquema fatorial $2 \times 5 \times 4$, correspondendo a duas fontes de $\mathrm{N}$ (ureia e esterco bovino), cinco doses de N (0 g planta- ${ }^{-1}$, $5 \mathrm{~g} \mathrm{planta}^{-1}, 10 \mathrm{~g} \mathrm{planta}^{-1}, 15 \mathrm{~g} \mathrm{planta}^{-1}$ e $\left.20 \mathrm{~g} \mathrm{planta}^{-1}\right) \mathrm{e}$ quatro densidades (51.282 plantas ha-1, 76.923 plantas ha $^{-1}$, 90.909 plantas ha-1 e 126.984 plantas ha ${ }^{-1}$ ). As fontes de $\mathrm{N}$ não interferiram no $\mathrm{pH}$, acidez total titulável e relação sólidos solúveis totais/acidez total titulável (SST/ATT). Entretanto, o teor de SST foi superior nas plantas adubadas com esterco bovino. A densidade de plantas não interferiu na qualidade de pós-colheita dos frutos. $\mathrm{O}$ aumento das doses de $\mathrm{N}$ fornecidas via ureia e esterco bovino influenciou somente a acidez total titulável dos frutos. Com a adição de $20 \mathrm{~g}_{\text {planta }}{ }^{-1}$ de $\mathrm{N}$-esterco e população de 126.984 plantas ha $^{-1}$ obteve-se o máximo rendimento líquido parcial de R\$132.096,48. No entanto, a dose de 19,75 g planta $^{-1}$ de N-ureia, na população de $119.686,00$ plantas ha $^{-1}$, resultou em rendimento líquido parcial de $\mathrm{R} \$ 154.997,15$.

PALAVRAS-CHAVE: Ananas comosus var. comosus; sólidos solúveis totais; rendimento econômico.

Estados produtores o Pará, Paraíba, Minas Gerais, Bahia e Rio de Janeiro (IBGE 2014).

No Brasil, vários estudos (Santana et al. 2001, Souza et al. 2009, Marques et al. 2011, Silva et al. 2012, Cardoso et al. 2013) têm relacionado a influência da adubação nitrogenada e da densidade de plantas à qualidade pós-colheita e produtividade do abacaxizeiro, principalmente para as cultivares

1. Trabalho recebido em jan./2014 e aceito para publicação em jan./2015 (http://dx.doi.org/10.1590/1983-40632015v4527998).

2. Universidade Estadual de Montes Claros (Unimontes), Departamento de Ciências Agrárias, Janaúba, MG, Brasil.

E-mails: f.deivisson@yahoo.com.br, rodinei.pegoraro@unimontes, ananias.medeiros@hotmail.com, paulo_apl17@hotmail.com, victor.maia@unimontes.br.

3. Empresa de Pesquisa Agropecuária de Minas Gerais (Epamig), Laboratório de solos, Nova Porteirinha, MG, Brasil.

E-mail:mauriciojba@yahoo.com.br. 
Smooth Cayenne e Pérola, porém, são escassos os estudos envolvendo a cultivar Vitória.

A cultivar Vitória, lançada recentemente, apresenta características agronômicas semelhantes ou superiores, em relação às cultivares Pérola e Smooth Cayenne. Os frutos são de polpa branca e possuem peso médio de $1,5 \mathrm{~kg}$, elevado teor de açúcares $\left(15,8^{\circ}\right.$ Brix $)$ e excelente sabor, podendo ser destinados ao mercado de consumo in natura e à agroindústria.

As fontes de nitrogênio mais usadas na adubação de plantas de abacaxizeiro são a ureia, sulfato de amônio e esterco bovino. As doses recomendadas variam em 6-10 $\mathrm{g}_{\text {planta }}{ }^{-1}$, devido aos distintos padrões de crescimento das cultivares. Ressalta-se que o uso de fontes orgânicas deve ser maximizado em solos de textura arenosa e/ou com baixos teores de matéria orgânica, devido aos benefícios à qualidade física, química e microbiológica do solo (Galvão et al. 2009).

O aumento da densidade de plantio, por sua vez, influencia diretamente na produtividade e qualidade do abacaxizeiro. O aumento da densidade de plantas favorece, principalmente, o cultivo para a indústria, em que a característica mais desejada é o aumento da produtividade, enquanto o tamanho do fruto é menos importante.

Souza et al. (2009) obtiveram decréscimo no peso, diâmetro médio dos frutos e do pedúnculo, rendimento de suco e número de mudas do tipo filhote, com o aumento da densidade populacional de 31.746 plantas ha ${ }^{-1}$ até 71.429 plantas ha $^{-1}$.

Outro fator em que a densidade de plantio interfere é o rendimento econômico, pelo aumento significativo de produtividade, uma vez que está atrelada diretamente ao rendimento econômico e ao custo de produção (Spironello et al. 1997).

Este estudo objetivou avaliar o efeito de diferentes densidades de plantio, fontes e doses de nitrogênio $(\mathrm{N})$ nas características de qualidade pós-colheita e na rentabilidade de abacaxizeiro Vitória irrigado.

\section{MATERIAL E MÉTODOS}

O estudo foi realizado de julho de 2009 a outubro de 2011, no município de Janaúba, no norte do Estado de Minas Gerais (15'43'47,4'S, $43^{\circ} 19^{\prime} 22,1$ ' W e altitude de $\left.516 \mathrm{~m}\right)$. O clima da região, segundo a classificação de Köppen, é do tipo Aw (tropical quente, apresentando inverno frio e seco), com precipitação pluviométrica média de, aproximadamente, $870 \mathrm{~mm}$, temperatura média anual de $24{ }^{\circ} \mathrm{C}$, insolação de 2.700 horas anuais e umidade relativa média de $65 \%$.

Após a seleção da área nativa para montagem do estudo, foram coletadas dez subamostras de solo, as quais foram homogeneizadas, dando origem a uma amostra composta. As amostragens dos solos foram realizadas na camada de $0-20 \mathrm{~cm}$, secas ao ar, destorroadas, passadas em peneira com abertura de malha de $2 \mathrm{~mm}$ e homogeneizadas. Retiraram-se alíquotas para a caracterização química e física (Embrapa 1997). Os resultados da análise química foram: $\mathrm{pH}\left(\mathrm{H}_{2} \mathrm{O}\right)=5,40 ; \mathrm{CO}=5,20 \mathrm{~g} \mathrm{~kg}^{-1}$ (Walkley-Black); $\mathrm{P}=3,70 \mathrm{mg} \mathrm{dm}^{-3}$ (extrator Mehlich 1); $\mathrm{K}=72,00 \mathrm{mg} \mathrm{dm}{ }^{-3} ; \mathrm{Ca}^{2+}=1,30 \mathrm{cmol}_{\mathrm{c}} \mathrm{dm}^{-3} ; \mathrm{Mg}^{2+}=$ $0,50 \mathrm{cmol}_{\mathrm{c}} \mathrm{dm}^{-3} ; \mathrm{Al}^{3+}=0,30 \mathrm{cmol}_{\mathrm{c}} \mathrm{dm}^{-3}\left(\mathrm{KCl}_{1} \mathrm{~mol} \mathrm{~L}^{-1}\right)$; $\mathrm{H}+\mathrm{Al}=1,80 \mathrm{cmol}_{\mathrm{c}} \mathrm{dm}^{-3}$ (extrator acetato de cálcio a $\mathrm{pH} 7,0) . \mathrm{Na}$ análise física, verificou-se areia $=64 \%$; silte $=9 \%$; e argila $=27 \%$.

Efetuou-se a limpeza da área e o preparo do solo por meio de gradagem e sulcamento. A correção do solo e a adubação de plantio foram realizadas com base nos resultados das análises química e física do solo, conforme Ribeiro et al. (1999). Foram utilizados $500 \mathrm{~kg} \mathrm{ha}^{-1}$ de calcário dolomítico, como fonte de cálcio e magnésio, distribuídos a lanço e incorporados à profundidade de $20 \mathrm{~cm}$, por meio de gradagem, dois meses antes do plantio. Foram utilizados $16,7 \mathrm{~g}$ planta $^{-1}$ de superfosfato simples, distribuídos nos sulcos de plantio.

As adubações de cobertura com $\mathrm{N}$ e K (aplicadas de modo localizado, próximo à linha de cultivo, em superfície) foram parceladas a partir do terceiro mês de cultivo após o plantio e espaçadas a cada dois ou três meses, de acordo com o crescimento das mudas de abacaxizeiro, até o período que antecedeu o início da indução floral, totalizando seis adubações. Foram aplicados $15 \mathrm{~g} \mathrm{planta}^{-1} \mathrm{de}_{2} \mathrm{O}$, utilizando-se o cloreto de potássio como fonte. Também foram utilizadas adubações foliares com ácido bórico $(0,07 \%)$, sulfato de zinco $(0,1 \%)$ e sulfato de cobre $(0,1 \%)$ no mesmo período da adubação com $\mathrm{N}$ e K em cobertura. Na implantação, foram utilizadas mudas micropropagadas da cultivar Vitória, previamente enviveiradas durante quatro meses, com o intuito de aumentar o tamanho das mudas. O plantio foi realizado com mudas apresentando altura média de 10-20 cm (peso médio das mudas de 100-200 g). 
O delineamento experimental utilizado foi o de blocos ao acaso, com três repetições. Foi empregado o esquema fatorial $2 \times 5 \times 4$, que consistiu de duas fontes de $\mathrm{N}$ (ureia e esterco bovino), cinco doses de N (0 g planta ${ }^{-1}, 5$ g planta $^{-1}, 10$ g planta $^{-1}$, 15 g planta $^{-1}$ e 20 g planta $\left.^{-1}\right)$ e quatro densidades de plantio (51.282 plantas ha-1 $^{-1}, 76.923$ plantas ha $^{-1}$, 90.909 plantas $\mathrm{ha}^{-1}$ e 126.984 plantas ha $\left.{ }^{-1}\right)$, correspondendo aos respectivos espaçamentos: $0,9 \mathrm{~m} \mathrm{x}$ $0,40 \mathrm{~m} \times 0,30 \mathrm{~m} ; 0,9 \mathrm{~m} \times 0,40 \mathrm{~m} \times 0,20 \mathrm{~m} ; 0,9 \mathrm{~m} \times$ $0,20 \mathrm{~m} \times 0,20 \mathrm{~m}$; e $0,9 \mathrm{~m} \times 0,15 \mathrm{~m} \times 0,15 \mathrm{~m}$. A utilização de densidade populacional acima de 50.000 plantas $^{\text {ha-1 }}$ foi justificada pelo maior potencial produtivo do abacaxizeiro Vitória, quando cultivado em sistema irrigado, e pela sua aptidão na produção de frutos para a indústria.

As doses de esterco bovino equivalentes às doses de $\mathrm{N}$ corresponderam a $0,532 \mathrm{~g}_{\text {planta }}{ }^{-1}$, 1,064 g planta $^{-1}, 1,596 \mathrm{~g} \mathrm{planta}^{-1}$ e 2,128 g planta ${ }^{-1}$. Os teores de nutrientes no esterco bovino foram: $\mathrm{N}=$ 0,94 dag $\mathrm{kg}^{-1}$ (digestão sulfúrica - método Kjeldahl);

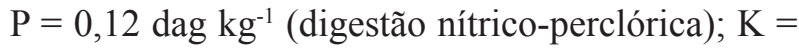
0,50 dag $\mathrm{kg}^{-1} ; \mathrm{S}=0,26 \mathrm{dag} \mathrm{kg}^{-1} ; \mathrm{Ca}=0,58$ dag $\mathrm{kg}^{-1}$;

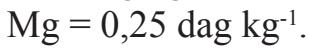

As parcelas foram constituídas por quatro fileiras duplas, contendo 10 plantas por fileira, totalizando 80 plantas por parcela. Destas foram avaliadas as seis plantas centrais das fileiras duplas centrais, totalizando 24 plantas úteis por parcela. Efetuou-se uma análise independente para cada fonte de $\mathrm{N}$ (ureia e esterco bovino).

O método de irrigação utilizado foi a aspersão convencional fixa, com aspersores de vazão nominal de $500 \mathrm{~L} \mathrm{~h}^{-1}$. Os emissores foram espaçados em $12 \mathrm{~m}$ ao longo da linha e $12 \mathrm{~m}$ entre as linhas. Foram realizadas três irrigações semanais, utilizando-se água proveniente do Rio Gorutuba. O tempo de irrigação variou de acordo com o coeficiente da cultura $(\mathrm{Kc})$ (0,5-1,2), durante o seu ciclo de desenvolvimento (Carvalho 1998).

Nos primeiros doze meses, as plantas daninhas foram controladas por capina manual e, após esse período, optou-se pela capina química, utilizando-se Ametrina e Haloxifope-R éster metílico, para controle das plantas de folhas largas e estreitas, respectivamente. Para controle de ácaros, foi utilizada Abamectina.

Por ocasião da colheita, dez frutos da parcela útil foram utilizados para a avaliação da massa média dos frutos com coroa, a fim de estimar a produtividade e rendimento econômico. Esses frutos foram classificados segundo a proposta do Programa Brasileiro para a Modernização da Horticultura (Ceagesp 2003). Cinco frutos com maturação uniforme foram coletados de cada parcela e encaminhados ao laboratório, para determinação do $\mathrm{pH}$, utilizando-se potenciômetro (AOAC 1997); teor de sólidos solúveis totais (SST), determinado na polpa triturada em processador doméstico, com posterior leitura direta e quantificação em refratômetro digital, sendo os resultados expressos em porcentagem (AOAC 1997); acidez total titulável (ATT), determinada com solução de $\mathrm{NaOH} 0,1 \mathrm{M}$, tendo como indicador a fenolftaleína $1 \%$, e os resultados expressos em gramas de ácido cítrico por $100 \mathrm{~g}$ de polpa; e relação sólidos solúveis totais/acidez total titulável (SST/ATT).

Para a avaliação econômica parcial, calculou-se o rendimento econômico bruto (produtividade $\mathrm{x}$ preço do kg de abacaxi), estimado na cotação média de comercialização praticada pelas unidades do Ceasa Minas (2013), no mês de dezembro de 2013, no valor de $\mathrm{R} \$ 1,72 \mathrm{~kg}^{-1}$ de fruto de abacaxi. Para o rendimento líquido parcial (RLP), foi calculado o custo adicional com as fontes de nitrogênio (ureia e esterco), de acordo com levantamento médio de preços do site de compra e venda MF Rural, sendo estimado em $\mathrm{R} \$ 906,40$ por tonelada de ureia (MF Rural 2013a) e R $\$ 150,00$ por tonelada de esterco (MF Rural 2013b), além do custo adicional com as mudas (R\$ 0,20 por muda; Embrapa 2013). A estimativa do rendimento líquido parcial foi obtida conforme a equação RLP $=$ RB $-($ CAFF + CAM $)$, em que $\mathrm{RLP}=$ rendimento líquido parcial $\left(\mathrm{R} \$ \mathrm{ha}^{-1}\right)$; $\mathrm{RB}=$ rendimento econômico bruto $\left(\mathrm{R} \$ \mathrm{ha}^{-1}\right)$; $\mathrm{CAFF}=$ custo adicional da fonte de fertilizante $\left(\mathrm{R} \$ \mathrm{ha}^{-1}\right) ; \mathrm{CAM}=$ custo adicional das mudas de abacaxizeiro ( $\mathrm{R} \$$ ha $\left.^{-1}\right)$.

A denominação de rendimento líquido parcial, para estimativa de retorno econômico líquido no cultivo do abacaxizeiro, deve-se à não inclusão de custos adicionais relacionados a mão de obra, transporte, máquinas, implementos agrícolas, irrigação, energia elétrica, etc.

A análise estatística dos dados incluiu as análises de variância e de regressão, a 5\%, e teste $\mathrm{F}$ $(\mathrm{p}<0,05)$. Os modelos foram ajustados com base na significância dos parâmetros, coeficiente de determinação e capacidade do modelo de explicar biologicamente o fenômeno. 


\section{RESULTADOS E DISCUSSÃO}

O aumento da densidade de plantio não interferiu nas características químicas do fruto, tanto para o $\mathrm{N}$ fornecido na forma de ureia quanto na forma de esterco de curral (Tabela 1). Esses resultados foram similares aos encontrados por Santana et al. (2001), que constataram que o aumento da densidade populacional não interfere nas características químicas e físicas dos frutos. Da mesma forma, Marques et al. (2011) e Silva et al. (2012) não observaram influência do acréscimo das doses de $\mathrm{N}$ nas características químicas dos frutos.

Foi observado efeito da fonte de $\mathrm{N}$ (ureia e esterco de curral) para o teor de sólidos solúveis e das doses de $\mathrm{N}$ somente para a acidez titulável. A fonte de $\mathrm{N}$ não interferiu no $\mathrm{pH}$, acidez total titulável e relação sólidos solúveis totais/acidez total titulável (SST/ATT). O teor de sólidos solúveis (Brix) foi superior nas plantas adubadas com esterco bovino (Tabela 2). Os principais nutrientes que estão envolvidos com os atributos de qualidade dos frutos são o nitrogênio e o potássio, este último sendo relacionado aos teores de sólidos solúveis totais (Brix). O esterco bovino atua também como fonte de potássio, o que

Tabela 1. Valores de F calculados na análise de variância e significância das fontes de variação referentes às características de pós-colheita, após a adição de doses crescentes de $\mathrm{N}$ na forma de ureia e esterco de curral, e diferentes densidades de plantio para o abacaxizeiro Vitória (Janaúba, MG, 2013).

\begin{tabular}{lcccc}
\hline \multicolumn{1}{c}{ Valores de F } & SST & pH & ATT & SST/ATT \\
\hline Fonte (F) & $9,87^{*}$ & $0,32^{\text {ns }}$ & $0,28^{\text {ns }}$ & $0,01^{\text {ns }}$ \\
Dose (D) & $0,29^{\text {ns }}$ & $2,04^{\text {ns }}$ & $2,57^{*}$ & $2,49^{\text {ns }}$ \\
Densidade (Ds) & $0,80^{\text {ns }}$ & $1,09^{\text {ns }}$ & $0,50^{\text {ns }}$ & $0,28^{\text {ns }}$ \\
D x F & $2,23^{\text {ns }}$ & $1,66^{\text {ns }}$ & $0,14^{\text {ns }}$ & $0,23^{\text {ns }}$ \\
Ds x F & $2,36^{\text {ns }}$ & $2,09^{\text {ns }}$ & $0,35^{\text {ns }}$ & $0,26^{\text {ns }}$ \\
Ds x D & $0,83^{\text {ns }}$ & $1,23^{\text {ns }}$ & $1,26^{\text {ns }}$ & $0,73^{\text {ns }}$ \\
Ds x D x F & $0,69^{\text {ns }}$ & $0,32^{\text {ns }}$ & $0,77^{\text {ns }}$ & $1,16^{\text {ns }}$ \\
\hline Média & 15,77 & 3,43 & 0,82 & 23,20 \\
\hline CV $(\%)$ & 7,54 & 4,82 & 18,64 & 19,54 \\
\hline ns *: não significativo e significativo a $5 \%$, respectivamente, pelo teste F. SST $=$ \\
sólidos solúveis totais; ATT = acidez total titulável.
\end{tabular}

Tabela 2. Médias do teor de sólidos solúveis totais (SST), pH, acidez total titulável (ATT) e relação SST/ATT da polpa de frutos do abacaxizeiro Vitória sob duas fontes de N (Janaúba, MG, 2013).

\begin{tabular}{|c|c|c|c|c|}
\hline Fonte de $\mathrm{N}$ & SST $(\%)$ & $\mathrm{pH}$ & ATT $(\%)$ & SST/ATT \\
\hline Ureia & $15,42 \mathrm{~b}$ & $3,44 \mathrm{a}$ & $0,82 \mathrm{a}$ & $23,25 \mathrm{a}$ \\
\hline Esterco & $16,11 \mathrm{a}$ & $3,42 \mathrm{a}$ & $0,83 \mathrm{a}$ & $23,15 \mathrm{a}$ \\
\hline
\end{tabular}

pode ter contribuído para elevar os teores de sólidos solúveis totais (Brix), nesse tratamento.

$\mathrm{O}$ aumento das doses de $\mathrm{N}$ fornecidas via ureia ou esterco propiciaram redução linear na acidez titulável dos frutos de abacaxizeiro (Figura 1). $\mathrm{O}$ incremento das doses de nitrogênio aumenta o tamanho dos frutos, causando diluição na acidez titulável. De acordo com Bhugaloo (1998), o teor de acidez na polpa é uma característica bastante importante e a baixa acidez da polpa proporciona fruto com pouco aroma e de gosto insípido, porém, quando a acidez é muito elevada, há redução na sensação de doçura, gerando uma fruta com sabor desagradável. $\mathrm{O} \mathrm{pH}$ é, portanto,uma característica importante para aceitação dos frutos pelo mercado consumidor.

Bhugaloo (1998) concluiu que a acidez dos frutos é superior nas menores doses de $\mathrm{N}$ fornecidas ao abacaxizeiro, enquanto Kist et al. (1991), trabalhando com a cultivar Smooth Cayenne, observaram que o teor de sólidos solúveis totais não sofreu influência significativa com o aumento da densidade de plantas de 34.190 plantas $\mathrm{ha}^{-1}$ para 61.540 plantas $\mathrm{ha}^{-1}$, o mesmo não acontecendo com a acidez do suco do fruto, que se elevou de forma linear, à medida que a densidade foi aumentada.

A utilização de esterco bovino como fonte de $\mathrm{N}$ propiciou o máximo rendimento líquido parcial de R\$ 132.096,48 ha-1, após a adubação com a dose máxima de $20 \mathrm{~g}_{\text {de }} \mathrm{N}_{\text {planta }}{ }^{-1}$ e densidade populacional de 126.984 plantas ha $^{-1}$ (Tabela 3). Nessa condição, obteve-se a produção de $108,91 \mathrm{t} \mathrm{ha}^{-1}$ de frutos com coroa, enquanto, no tratamento controle (sem adubação nitrogenada e população de 51.282 plantas ha $^{-1}$ ), a produção de frutos foi inferior a $30 \mathrm{tha}^{-1}$ (Figura 2a).

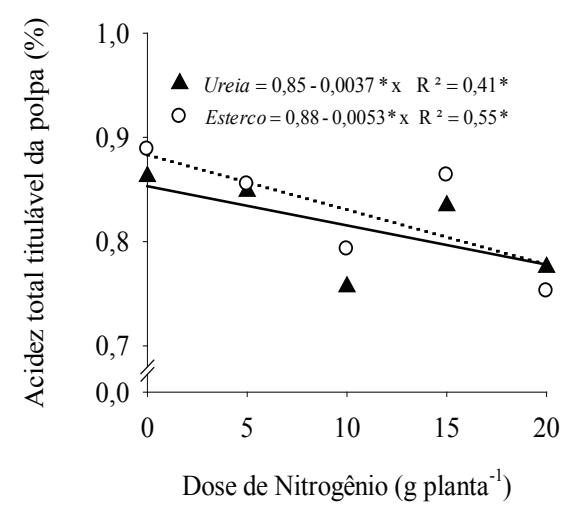

Figura 1. Acidez total titulável da polpa em abacaxizeiro Vitória influenciada por diferentes doses e fontes de N (Janaúba, MG, 2013). 
Tabela 3. Estimativas de doses de N, adensamento, produtividade e levantamento econômico (rendimento bruto, custo com a fertilização nitrogenada na forma de ureia ou esterco, custo de aquisição das mudas e rendimento líquido parcial) ajustados pelos modelos de regressão, para obtenção da máxima eficiência técnica e econômica no abacaxizeiro Vitória irrigado (Janaúba, MG, 2013).

\begin{tabular}{|c|c|c|c|c|c|c|}
\hline \multirow{3}{*}{ Característica } & \multirow{2}{*}{\multicolumn{2}{|c|}{ Pontos de máxima }} & \multirow{2}{*}{\multicolumn{2}{|c|}{$\frac{\text { Dose de N }}{\text { g planta }^{-1}}$}} & \multirow{2}{*}{\multicolumn{2}{|c|}{$\begin{array}{c}\text { Adensamento } \\
\text { plantas ha }^{-1}\end{array}$}} \\
\hline & & & & & & \\
\hline & Ureia $^{\&}$ & Esterco $^{\#}$ & Ureia $^{\&}$ & Esterco $^{\#}$ & Ureia $^{\&}$ & Esterco $^{\#}$ \\
\hline Produtividade & $107,44 \mathrm{t} \mathrm{ha}^{-1}$ & $108,91 \mathrm{t} \mathrm{ha}^{-1}$ & 20,70 & 20,00 & $124.196,00$ & $126.984,00$ \\
\hline Rendimento bruto & $\mathrm{R} \$ 184.802,29$ & $\mathrm{R} \$ 189.055,18$ & 20,69 & 20,00 & $124.196,00$ & $126.984,00$ \\
\hline Custo do $\mathrm{N}$ & $\mathrm{R} \$ \quad 4.965,94$ & $\mathrm{R} \$ 31.579,90$ & - & - & - & - \\
\hline Custo das mudas & $\mathrm{R} \$ 24.839,20$ & $\mathrm{R} \$ \quad 25.378,80$ & - & - & - & - \\
\hline Rendimento líquido & $\mathrm{R} \$ 154.997,15$ & $\mathrm{R} \$ 132.096,48$ & 19,75 & 20,00 & $119.686,00$ & $126.984,00$ \\
\hline
\end{tabular}

\& As doses de $\mathrm{N}$ e adensamento populacional para obtenção e indicação da máxima produtividade, rendimento bruto e líquido parcial foram retirados dos modelos de regressão não linear gaussainos descritos na Figura 2. " Em virtude do ajuste de modelos não lineares sem ponto de máxima, foram utilizados a maior dose de $\mathrm{N}$ na forma de esterco $\left(20 \mathrm{~g} \mathrm{planta}^{-1}\right)$ e adensamento (126.984 plantas ha $\left.^{-1}\right)$ para a estimativa de máxima produtividade e rendimento econômico.
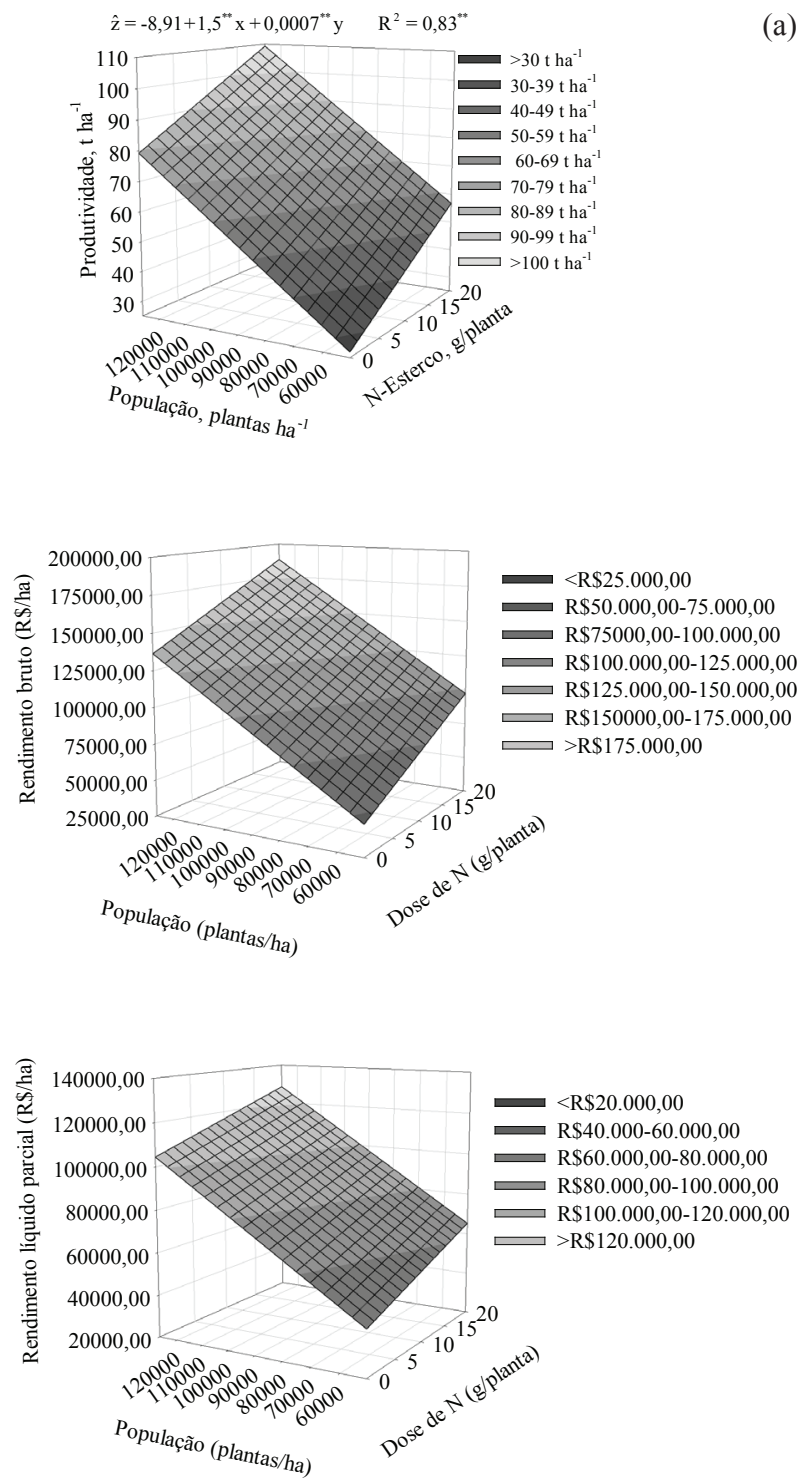

(a)
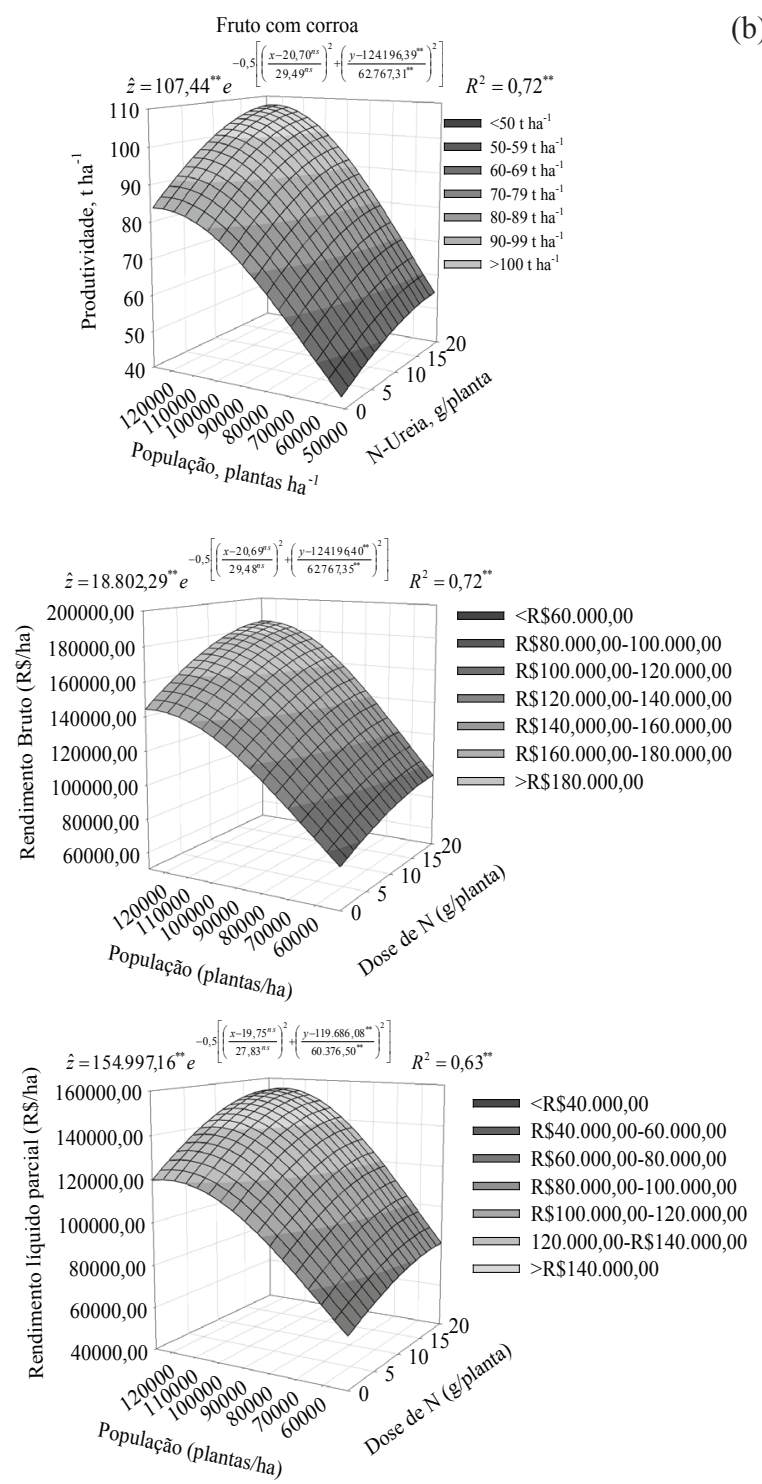

Figura 2. Rendimento líquido parcial obtido para o abacaxizeiro Vitória irrigado, após a adição de diferentes doses de $\mathrm{N}$ e densidades de plantio (Janaúba, MG, 2013). (a) = esterco bovino e (b) = ureia. 
No tratamento controle, os frutos são de baixa qualidade para comercialização in natura, em função do tamanho reduzido. $\mathrm{O}$ maior rendimento líquido parcial com o incremento das doses de $\mathrm{N} \mathrm{e}$ densidade populacional deveu-se, principalmente, ao maior número de frutos colhidos por unidade de área.

De acordo com estudo conduzido por Melo et al. (2004), o aumento da densidade de plantio de 31.250 plantas ha-1 para 55.555 plantas $\mathrm{ha}^{-1}$ de abacaxizeiro Pérola propiciou o rendimento líquido por hectare de $\mathrm{R} \$ 11.976,20$, demonstrando a importância do aumento do número de plantas por hectare para a obtenção de maiores lucros com o cultivo de abacaxizeiro.

A utilização de ureia como fonte de $\mathrm{N}$ propiciou o máximo rendimento líquido parcial de $\mathrm{R} \$ 154.997,15$, com a aplicação de 19,75 g planta $^{-1}$ de $\mathrm{N}$, na densidade populacional de 119.686,00 plantas ha-1 (Tabela 3). Nessa condição, obteve-se produção de 107,44 $\mathrm{t} \mathrm{ha}^{-1}$ de frutos (Figura 2b). Notou-se que a utilização de ureia como fonte de $\mathrm{N}$ propiciou maior rendimento líquido parcial, quando comparada ao esterco bovino, pois o custo monetário do nitrogênio por unidade de área (hectare) foi considerado $635,9 \%$ inferior, com a utilização da ureia como fonte de fertilizante nitrogenado (Tabela 3). Porém, é importante ressaltar que as fontes orgânicas, mesmo aumentando os custos de produção, exercem grande importância nas características físicas do solo, elevando os teores de matéria orgânica, contribuindo para uma boa agregação e liberando nitrogênio lentamente, evitando perdas principalmente por lixiviação.

Segundo Silva et al. (2012), o aumento das doses de $\mathrm{N}$ na forma de ureia implicou em incremento linear positivo na produtividade da cultivar Vitória. Santana et al. (2001) observaram aumento de produtividade de $8,27 \mathrm{tha}^{-1}$ para cada 10.000 plantas a mais, em plantios variando em 51.280-82.222 plantas ha $^{-1}$ de abacaxizeiro Smooth Cayenne, em condições de sequeiro, e Melo et al. (2010), no cultivo de bananeira Prata-anã, observaram rendimento de $27 \%$ na lucratividade, com elevação das doses de nitrogênio e potássio e redução nos custos de produção de até 40,54 \%. Esses estudos destacam a adubação nitrogenada e o espaçamento de plantio como características de grande influência no rendimento de frutos e, possivelmente, no rendimento econômico de cultivo de abacaxizeiro.

\section{CONCLUSÕES}

1. O esterco bovino propicia melhores teores de sólidos solúveis totais (Brix) aos frutos de abacaxizeiro Vitória.

2. O aumento das doses de nitrogênio com a fonte ureia resulta em efeito negativo na acidez titulável dos frutos.

3. O aumento da densidade de plantas não interfere nas características químicas dos frutos.

4. O adensamento e o aumento das doses de nitrogênio com a fonte ureia e esterco bovino promovem aumento no rendimento líquido parcial do cultivo irrigado do abacaxizeiro Vitória.

\section{REFERÊNCIAS}

ASSOCIATION OF OFFICIAL ANALYTICAL CHEMISTS (AOAC). Official methods of analysis of the Association of Official Analytical Chemists International. 3. ed. Washington, DC: AOAC, 1997.

BHUGALOO, R. A. Effects of different levels of nitrogen on yield and quality of pineapple variety Queen Victoria. Réduit: Food Agricultural Research Council, 1998.

CARDOSO, M. M. et al. Crescimento do abacaxizeiro 'Vitória' irrigado sob diferentes densidades populacionais, fontes e doses de nitrogênio. Revista Brasileira de Fruticultura, Jaboticabal, v. 35, n. 3, p. 769-781, 2013.

CARVALHO, A. M. Irrigação no abacaxizeiro. Informe Agropecuário, Belo Horizonte, v. 19, n. 1, p. 58-61, 1998.

CENTRAIS DE ABASTECIMENTO DE MINAS GERAIS S. A. (Ceasa Minas). Preço mais comum no Estado de Minas Gerais. 2013. Disponível em: $<$ http://200.198.51.221:86/precosofertas/cstprecos maiscomumMG/cst precosmaiscomumMG.php>. Acesso em: 25 out. 2013.

COMPANHIA DE ENTREPOSTOS E ARMAZÉNS GERAIS DE SÃO PAULO (Ceagesp). Programa brasileiro para modernização da horticultura: normas de classificação do abacaxi. São Paulo: Central de Qualidade em Horticultura, 2003. (Documentos, 24).

EMPRESA BRASILEIRA DE PESQUISA AGROPECUÁRIA (Embrapa). Centro Nacional de Pesquisa de Solos. Manual de métodos de análise de solo. 2. ed. Rio de Janeiro: Embrapa, 1997.

EMPRESA BRASILEIRA DE PESQUISA AGROPECUÁRIA (Embrapa). Página de negócio de cultivares. 2013. Disponível em: $<$ http://snt.sede.Embrapa. $\mathrm{br} / \operatorname{produtos} /$ mostrarproduto/211/ $\mathrm{s}$. Acesso em: 12 nov. 2013. 
FOOD AND AGRICULTURE ORGANIZATION (FAO). Produção de abacaxi. 2010. Disponível em: < http://faostat. fao.org $/$ site $/ 567 \% 20 /$ DesktopDefault.aspxPageID=567>. Acesso em: $11 \mathrm{dez} .2013$.

GALVÃO, S. R. S. et al. Acumulação de nutrientes em solos arenosos adubados com esterco bovino. Pesquisa Agropecuária Brasileira, Brasília, DF, v. 43, n. 1, p. 99$105,2009$.

INSTITUTO BRASILEIRO DE GEOGRAFIA E ESTATÍSTICA (IBGE). Levantamento sistemático da produção agrícola. 2014. Disponível em: <ftp://ftp.ibge. gov.br/Producao_Agricola/Levantamento_Sistematico da_Producao_Agricola_\%5Bmensal $\% 5 \bar{D} /$ Fasciculo/ 1spa_201405.pdf >. Acesso em: 22 jul. 2014.

KIST, H. G. K. et al. Influência de densidades de plantio do abacaxi cv. Smooth Cayenne. Pesquisa Agropecuária Brasileira, Brasília, DF, v. 26, n. 3, p. 325-330, 1991.

MARQUES, L. S. et al. Produtividade e qualidade de abacaxizeiro cv. Smooth Cayenne, cultivado com aplicação de doses e parcelamentos do nitrogênio, em Guaraçi - SP. Revista Brasileira de Fruticultura, Jaboticabal, v. 33, n. 3, p. 1004-1014, 2011.

MELO, A. S. et al. Rendimento, qualidade da fruta e lucratividade do abacaxizeiro cv. Pérola em diferentes espaçamentos. Revista de Ciências Agrárias, Manaus, n. 41, p. 185-192, 2004.

MELO, A. S. et al. Aspectos técnicos e econômicos da bananeira 'Prata-anã' sob fertirrigação nos tabuleiros costeiros de Sergipe. Ciência e Agrotecnologia, Lavras, v. 34, n. 3, p. 564-571, 2010.
MF RURAL. Fertilizante ureia. 2013a. Disponível em: < http://comprar-vender.mfrural.com.br/ detalhe/ fertilizantes-ureia-prill-118806.aspx $>$. Acesso em: 12 nov. 2013.

MF RURAL. Esterco bovino. 2013b. Disponível em: < http:/comprar-vender.mfrural.com.br/ detalhe/estercobovino-121215.aspx>. Acesso em: 12 nov. 2013.

RIBEIRO, A. C.; GUIMARÃES, P. T. G.; ALVAREZ V., V.H. Recomendações para o uso de corretivos e fertilizantes em Minas Gerais: 5a aproximação. Viçosa: Comissão de Fertilidade do Solo do Estado de Minas Gerais, 1999.

SANTANA, L. L. A. et al. Altas densidades de plantio na cultura do abacaxi cv. Smooth Cayenne, sob condições de sequeiro. Revista Brasileira de Fruticultura, Jaboticabal, v. 23, n. 2, p. 353-358, 2001.

SILVA, A. L. P. et al. Resposta do abacaxizeiro 'Vitória' a doses de nitrogênio em solos de tabuleiros costeiros da Paraíba. Revista Brasileira de Ciência do Solo, Viçosa, v. 36, n. 2, p. 447-456, 2012.

SOUZA, O. P. et al. Qualidade do fruto e produtividade do abacaxizeiro em diferentes densidades de plantio e lâminas de irrigação. Pesquisa Agropecuária Brasileira, Brasília, DF, v. 44, n. 5, p. 471-477, 2009.

SPIRONELLO, A. et al. Avaliação agrotecnológica e do ciclo de variedades de abacaxizeiro em duas densidades, em Votuporanga (SP). Bragantia, Campinas, v. 56, n. 2, p. 333-342, 1997. 